\title{
Letter to Editor: The Significance of Histologically "Large Normal" Parathyroid Glands in Primary Hyperparathyroidism
}

\author{
Mallika Dhanda $^{1}$ (1) $\cdot$ Sabaretnam Mayilvaganan $^{1} \cdot$ VNSSVAMS Mahalakshmi $^{1} \cdot$ \\ Suneel Mattoo ${ }^{1} \cdot$ Amit Agarwal $^{1}$
}

Published online: 27 February 2020

(C) Société Internationale de Chirurgie 2020

The novel article "The Significance of Histologically "Large Normal" Parathyroid Glands in Primary Hyperparathyroidism" by Krawitz et al. [1] was discussed in our Journal club as it was a pertinent issue for our department. We have often encountered similar Large but histologically normal parathyroid glands in both thyroidectomies as well as parathyroidectomies.

While this article has encouraged us to study the same in our population, it has opened up a world of queries.

It is a fascinating entity considering that in spite of normal amount of acinar tissue, there is a significant increase in parathyroid hormone secretion. We debated if the proportion of acinar tissue to fat remained normal with an absolute increase in both?

We also wonder if the authors classified these large glands further into $<100 \mathrm{~g}$ and $>100 \mathrm{~g}$ and if a significant difference was seen biochemically or clinically between the two. Since the weight of the gland would have been available postoperatively, we further question if there was an average size (in $\mathrm{mm}$ ) that the authors could recommend for Large Normal Parathyroids.
The authors have published their advocacy for use of IOPTH in this rare scenario. We would also like to know their perspective on frozen section [2] and if its use is justified? With the presence of fat on frozen section along with a large sized gland identified intraoperatively, can a diagnosis of "Large Normal Parathyroid" not be made?

\section{References}

1. Krawitz R, Glover A, Koneru S, Jiang J, Di Marco A, Gill AJ, Aniss A, Sywak M, Delbridge L, Sidhu S (2019) The significance of histologically "large normal" parathyroid glands in primary hyperparathyroidism. World J Surg. https://doi.org/10.1007/ s00268-019-05302-6

2. Roth SI, Gallagher MJ (1976) The rapid identification of "normal" parathyroid glands by the presence of intracellular fat. Am J Pathol 84(3):521

Publisher's Note Springer Nature remains neutral with regard to jurisdictional claims in published maps and institutional affiliations.

Mallika Dhanda

dmallika87@gmail.com

1 Department of Endocrine and Breast Surgery, Sanjay Gandhi

Postgraduate Institute of Medical Sciences, Lucknow,

Uttar Pradesh, India 